\title{
Abravanel Nicole, Benoit-Roubinowitz Martine, Delmaire Danielle (éds), Histoire et conscience. Il y a soixante ans, l'ouverture des camps d'extermination, Actes des journées d'études de Lille-Amiens (31 janvier 2005 et 3 février 2005)
}

Villeneuve d'Ascq, Édition du Conseil Scientifique de l'université Charles-de-Gaulle - Lille 3, 2007

Claudia Zudini

\section{OpenEdition Journals}

Édition électronique

URL : http://journals.openedition.org/cei/949

DOI : 10.4000/cei.949

ISSN : 2260-779X

Éditeur

UGA Éditions/Université Grenoble Alpes

Édition imprimée

Date de publication : 15 mai 2008

Pagination : 397-398

ISBN : 978-2-84310-121-2

ISSN : $1770-9571$

\section{Référence électronique}

Claudia Zudini, « Abravanel Nicole, Benoit-Roubinowitz Martine, Delmaire Danielle (éds), Histoire et conscience. Il y a soixante ans, l'ouverture des camps d'extermination, Actes des journées d'études de Lille-Amiens (31 janvier 2005 et 3 février 2005) », Cahiers d'études italiennes [En ligne], 7| 2008, mis en ligne le 15 novembre 2009, consulté le 21 septembre 2020. URL : http://journals.openedition.org/cei/ 949 ; DOI : https://doi.org/10.4000/cei.949 


\section{COMPTES RENDUS DE LECTURES}

Abravanel Nicole, BenOIT-RoubinOwitz Martine, Delmaire Danielle (éd.), Histoire et conscience. Il y a soixante ans, l'ouverture des camps d'extermination, Actes des journées d'études de Lille-Amiens (31 janvier 2005 et 3 février 2005), Villeneuve d'Ascq, Édition du Conseil scientifique de l'université Charles-de-Gaulle - Lille 3, 2007, 169 p.

La parution de cet ouvrage collectif vient souligner le soixantième anniversaire de l'ouverture des camps d'extermination nazis par le biais d'une étude qui prend en compte aussi bien l'aspect historique que la réflexion sur la prise de conscience individuelle et collective face à la Shoah. Le recueil rassemble des communications d'historiens, d'historiens de l'art et de spécialistes de littérature, des témoignages de déportés et de jeunes gens qui se sont rendus à Auschwitz, ainsi qu'un poème inédit de Julien Delmaire, l'objectif pédagogique commun aux différentes contributions étant «le refus de l'oubli, la mémoire, la transmission - notamment à un public étudiant parfois très démuni - et la justesse des mots» (p. 11). Cet aspect lexical fait notamment l'objet de l'intervention d'Anne Grynberg, dans le cadre de la réflexion plus générale autour de l'acte de commémorer, par laquelle cet ouvrage s'ouvre ("Auschwitz: Commémorer et nommer») et dont nous soulignerons aussi, parmi d'autres, l'interrogation sur l'usage public et sur l'institutionnalisation de la mémoire menée par George Bensoussan et par Enzo Traverso. La notion de résistance est convoquée dans la deuxième partie du livre ("Auschwitz: Résistance») selon deux acceptions différentes: la résistance concrète des Juifs en France et en Europe orientale, et celle intérieure des Allemands devant l'acceptation de l'Holocauste. Le questionnement historique cède la place aux récits des survivants et l'expression poétique de la douleur dans la partie médiane du recueil ("Auschwitz: Témoignages»): le CD accompagnant les actes rend directement compte de ces témoignages. Le quatrième volet de cet ouvrage ("Auschwitz: Secret et conscience») se 
concentre sur l'élaboration de la prise de conscience: en analysant le sens de la désobéissance chez de hauts fonctionnaires qui réagirent de manière différente à la persécution des Juifs, Paul Zawadki vient notamment souligner la dimension individuelle, intérieure et transcendante à la contrainte politique et au Zeitgeist, de ce que l'on appelle désobéissance civile. La dernière partie de l'ouvrage aborde l'approche littéraire et picturale de l'horreur des camps ("Auschwitz: Paroles, silences, images»): le témoignage de Primo Levi y a une place majeure, comme le montre Giuditta Isotti-Rosowsky, qui s'arrête sur le rôle problématique de la mémoire de l'écrivain témoin, notamment de la mémoire négative qui serait susceptible de saborder ses propos, en l'obligeant à se heurter à la limite de son propre témoignage, à mettre à l'épreuve celui-ci sur le plan de la vérification historique.

Claudia Zudini 